\title{
Motive and Millennial Self Concept in Understanding Digital Transactions through Phenomenology Approach
}

\author{
Ulfa Yuniati', Firman Katon ${ }^{2}$ \\ ${ }^{1,2}$ Department of Communication Science Faculty of Social Humaniora, \\ Universitas Muhammadiyah Bandung \\ J1. Soekarno Hatta No.752, Bandung \\ Email: ulfa.yuniati@gmail.com ${ }^{1 *}$; katonfirman10@gmail.com² \\ *Corresponding author
}

\begin{abstract}
Financial technology (FinTech) such as E-Money makes individuals tend to be consumptive. The purpose of this study was to analyze the self-concept of the millennial generation of UMBandung students in interpreting digital transactions, motives (past and future) in using and utilizing electronic money or electronic wallets. The research object determined was OVO. The research method used is qualitative with Alfred Scutz's phenomenological approach which examines the self-concept of using electronic wallets in interpreting transaction innovation, motives for using digital transaction services to behavior that is depicted from selfconcept in UMBandung millennial students. The results of this study obtained (1) the past motive actions of students using digital transaction payments are the use of time in ordering food or drinks and transportation, (2) future motive actions add to experience in technology, enjoy promos, and later change to digital wallets which provides good service and satisfies needs. The self-concept of UMBandung students tends to be negative with consumptive behavior by paying attention to the discounts offered by OVO. The contribution of this research is in the form of recommendations to companies OVO, Gopay, DANA, LinkAja in order to facilitate transaction services by adding outlets that can participate in promos.
\end{abstract}

Keywords: Cashless Society; E-Wallet; Motive and Self-Concept; The Millennial Generation

\begin{abstract}
Abstrak
Financial technology (FinTech) seperti E-Money menjadikan individu cenderung konsumtif. Tujuan penelitian ini untuk menganalisis konsep diri generasi milenial mahasiswa UMBandung dalam memaknai transaksi digital, motif (masa lalu dan akan datang) dalam menggunakan dan memanfaatkan uang elektronik atau dompet elektronik. Objek penelitian yang ditentukan adalah OVO. Metode penelitian yang digunakan adalah kualitatif dengan pendekatan fenomenologi Alfred Scutz yang mengkaji konsep diri penggunaan dompet elektronik dalam memaknai inovasi transaksi, motif dalam menggunakan layanan transaksi digital hingga perilaku yang digambarkan dari konsep diri pada mahasiswa milenial UMBandung. Hasil penelitian ini memperoleh (1) tindakan motif masa lalu mahasiswa menggunakan pembayaran transaksi digital adalah pemanfaatan waktu dalam memesan makanan atau minuman serta transportasi, (2) tindakan motif di akan datang menambah pengalaman dalam teknologi, menikmati adanya promo, dan nantinya berganti ke dompet digital yang memberikan pelayanan baik dan memuaskan kebutuhan. Konsep diri mahasiswa UMBandung cenderung negatif yang beperilaku konsumtif dengan memperhatikan diskon yang ditawarkan OVO. Kontribusi penelitian ini berupa rekomendasi kepada perusahaan OVO, Gopay, DANA, LinkAja agar memudahkan layanan transaksi dengan menambahkan gerai-gerai yang dapat mengikuti promo.
\end{abstract}

Kata kunci: Cashless Society; Dompet Digital; Konsep Diri dan Motif; Generasi Milenial;

\section{Pendahuluan}

Dewasa ini, kehidupan manusia sudah menjadi sangat berkembang dengan adanya ide maupun inovasi yang sudah diciptakan. Ide dan inovasi yang diciptakan didukung pula dengan hadirnya internet sangatlah membantu dalam kegiatan manusia sehari-hari. Seiring dengan perkembangan teknologi, salah satu

pemanfaatan internet yang saat ini banyak di pakai ialah pelaksanaan transaksi menggunakan $e$-wallet atau yang biasa disebut dengan dompet digital atau lebih dikenal dengan cashless society, gaya hidup tanpa uang tunai. Hal ini tidak bisa dilepaskan dari para generasi milenial yang telah melek teknologi dan internet. 
Cashless society adalah sebutan yang merujuk pada masyarakat yang dalam bertransaksi, tidak lagi menggunakan uang fisik, melainkan melalui perpindahan informasi finansial secara digital. Dalam bertransaksi sehari-hari, masyarakat tidak menggunakan uang nyata, melainkan uang digital (Bintarto, 2018).

Dompet digital adalah jenis akun prabayar yang dilindungi dengan kata sandi di mana pengguna dapat menyimpan uang untuk setiap transaksi online, seperti pembayaran untuk makanan, belanja barang online, dan tiket penerbangan. Dompet digital dapat di unduh secara gratis melalui smartphone setiap orang (Rosmayanti, 2019).

Dompet digital telah menjadi bagian dari kehidupan sehari-hari masyarakat dimana dalam waktu seminggu sekitar satu hingga dua kali menggunakan pembayaran transaksi mencapai $68 \%$.

Perkembangan teknologi informasi pada bidang ekonomi menyebabkan inovasi teknologi seperti financial technology (FinTech) mengenai penggunaan uang non tunai atau cashless semakin banyak digunakan oleh layanan e-commerce, Link-Aja, DANA, maupun layanan transportasi online seperti gojek, grab yang telah menggunakan fitur layanan transaksi digital.

Adanya dompet digital seperti OVO, Gopay, DANA, LinkAja menjadikan manusia konsumtif dikarenakan mudahnya layanan

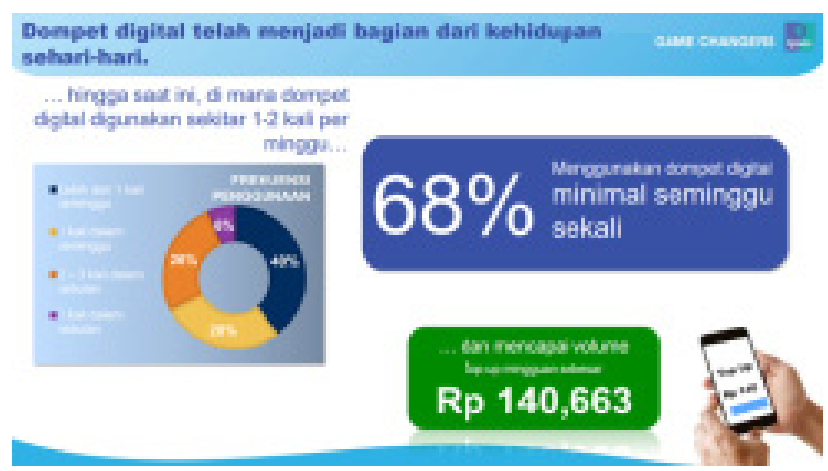

Gambar 1. Dompet Digital Menjadi Kehidupan Sehari-hari

Sumber: https://nextren.grid.id (Prama, 2020) transaksi melalui digital dan adanya promo yang ditawarkan. Berdasarkan riset yang dilakukan oleh (Pangestu, 2020) dalam menunjukkan bahwa penggunaan dompet digital dapat membuat konsumen muda lebih konsumtif. Hal senada juga dikatakan oleh Tejasari Assad Perencana Tata Kelola Keuangan pada laman CNN, jangan sampai ter jangan sampai terjebak sifat konsumtif hanya karena perkara diskon (Fauzie, 2019). Penggunaan layanan transaksi tersebut merupakan salah satu bentuk komunikasi pada inovasi yang mendorong lahirnya pembayaran secara digital dan komunikasi interpersonal antar konsumen terlibat di dalam penggunaan layanan ini. Peran media massa dalam menyebarkan informasi pun menjadi keterlibatan langsung dalam proses komunikasi.

Transformasi pembayaran secara digital pun merupakan strategi komunikasi yang dilakukan perusahaan fintech juga peran media massa, agar dapat menarik banyak konsumen dalam menggunakan layanan transaksi elektronik. Transaksi yang paling sering digunakan menurut hasil riset lembaga riset berbasis aplikasi, snapchart yaitu transaksi retail(28\%), pemesanan transportasi online (27\%), dan pemesanan makanan online (20\%). Sisanya, untuk transaksi e-commerce (15\%) dan pembayaran tagihan (7\%). Segmen transaksi pemesanan transportasi online dan pengiriman makanan online, data penelitian Snapcart menunjukkan posisi OVO sebagai dompet digital layanan Grab dan Grab Food menunjukkan $71 \%$ responden yang menggunakan OVO untuk transaksi ini (Sutriyanto, 2019).

Pada gambar 1 dapat dikatakan bahwa uang elektronik untuk transaksi harian seperti transportasi, pengiriman makanan cepat saji, dan belanja telah popular di kalangan konsumen Indonesia terutama pada kaum generasi milenial maupun generasi $\mathrm{z}$ yang dikenal fasih menggunakan teknologi. Penggunaan layanan transaksi digital di kalangan generasi milenial menjadikan ketertarikan peneliti dalam memanfaatkan tren teknologi (uang elektronik). 

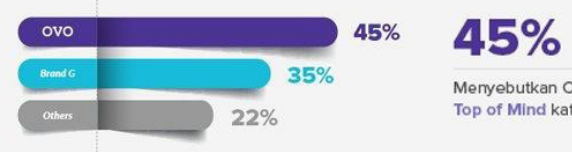

Menyebutkan ovo sebagai Top of Mind kategori dompet digital

Sumber: Survey tatap muka Kantar 2019 terhadap 1200 responden d1 8 koto

Gambar 2. OVO sebagai top of mind dompet digital Sumber: https://www.tribunnews.com (2019)

Salah satu layanan transaksi yang dimanfaatkan generasi milenial adalah OVO yanh ada pada fitur transportasi online grab. Layanan OVO adalah sebuah aplikasi smart memberikan layanan pembayaran dan transaksi secara online (OVO Cash), juga bisa berkesempatan untuk mengumpulkan poin setiap kali melakukan transaksi pembayaran melalui OVO. OVO cash dapat digunakan untuk berbagai macam pembayaran yang telah bekerja sama dengan OVO menjadi lebih cepat. (www.OVO id/faq). OVO mendapatkan predikat sebagai top of mind kategori dompet digital dari masyarakat sebesar $45 \%$.

Penelitian terdahulu yang dijadikan acuan untuk kerangka pemikiran konsep diri diantaranya yang dilakukan Pertiwi (2018), mengenai konsep diri wanita Shopaholic di kota Bandar Lampung mengatakan bahwa konsep diri memberikan kerangka acuan yang mempengaruhi manajemen seseorang terhadap situasi dan hubungan dengan orang lain. Hasil penelitian tersebut mengungkapkan bahwa konsep diri wanita shopaholic di Kota Bandar Lampung kepada konsep diri positif karena informan lebih percaya diri, terbuka dan memiliki kepribadian ekstrovert. Faktor pendukung lain mempengaruhi konsep diri informan yang positif.

Penelitian yang dilakukan Wirman (2012) mengenai pengalaman komunikasi dan konsep diri perempuan gemuk di Pekanbaru mengungkapkan bahwa partisipan pada usia anak-anak hingga remaja memiliki konsep diri lebih positif dibandingkan dengan partisipan dewasa cenderung konsep diri negatif. Alasan untuk menurunkan berat badannya adalah untuk hidup sehat dan penampilan tubuh. Acuan untuk penelitian terdahulu motif adalah yang dilakukan Wulandari (2016) mengenai motif dan makna diri pria penata rias di kota Pekanbaru dalam perspektif fenomenologi. Hasil penelitian tersebut didapatkan bahwa motif karena (because motive) yaitu teman yang baik, berkah dari Tuhan dan hobi. Motif tujuan (in order to motive) yaitu ingin menciptakan tata rias sekolah, karir yang baik, dan mengubah pandangan masyarakat. Adapun hasil dari pengalaman komunikasi ada yang menyenangkan dan tidak menyenangkan.

Penelitian motif yang dilakukan Hermaniawati dan Listyani (2015) mengenai motif pemanfaatan layanan elektronik tiket (E-Ticketing) olehpenggunakeretaapidiSurabaya menunjukkan dua motif pengguna kereta api yaitu motif karena dan motif tujuan. Motif sebab dikategorikan menjadi faktor percaya, latar belakang pengalaman antri, kemudahan dalam pembelian tiket dan juga ketepatan penyampaian informasi. Motif tujuan dapat dikategorikan menjadi efisiensi waktu dan biaya, mengikuti zaman, dan faktor keamanan serta kenyamanan.

Penelitian terdahulu terletak pada pengalaman komunikasiyang ditinjau dari konsep diri dan motif. Adapun penelitian terdahulu yang membahas mengenai penggunaan uang elektronik atau dompet elektronik sebagai cashless society (Bintarto, 2018; Houston, 2020; Rif'ah, 2019) masih sedikit, jika dibandingkan dengan penelitian yang membahas mengenai motif dan konsep diri pada komunitas dan individu. Melihat keadaan determinasi teknologi, peneliti ingin mengkaji dari perspektif konsep diri penggunaan dompet elektronik, motif dalam menggunakan layanan transaksi digital, perilaku mahasiswa UMBandung dalam memaknai layanan transaksi digital, dan komunikasi interpersonal. 
Pendekatan yang digunakan dalam mengetahui motif, konsep diri adalah fenomenologi Alfred Scutz. Konsep diri memiliki dua kualitas atau valensi, yaitu: konsep diri positif dan negatif, konsep diri meliputi tiga aspek yaitu yaitu fisik, psikis dan sosial. Fisik dan psikis merupakan faktor yang terjadi dalam diri sendiri yaitu faktor internal sedangkan sosial yaitu faktor eksternal dari lingkungan keluarga atau lingkungan pergaulan seperti lingkungan pendidikan dan lingkungan pekerjaan (Pertiwi, 2018).

\section{Perilaku Konsumtif}

Generasi milenial atau dikenal dengan Gen Y lahir di era kemajuan teknologi. Generasi milenial memanfaatkan teknologi dan informasi untuk mencari kebutuhan informasi, mengumpulkan informasi untuk dapat memutuskan membeli suatu produk atau menggunakan jasa. Generasi milenial memiliki pandangan positif dengan kehadiran teknologi dan informasi memengaruhi kehidupan daripada generasi sebelumnya (Hidayatullah, Waris, \& Devianti, 2018).

Generasi milenial dalam menikmati teknologi informasi tentunya menjadi bagian dari karakteristikgenerasimilenial.Haliniberdasarkan artikel yang dilansir dari laman hitss.com dalam Hidayatullah, generasi milenial yaitu: 1) milenial lebih percaya user generated content (UGC); 2) milenial lebih memilih ponsel disbanding $\mathrm{TV}$; 3) milenial wajib punya media social; 4) milenial cenderung tidak loyal namun bekerja efektif; 6) milenial memanfaatkan teknologi dan informasi; dan 7) milenial cenderung lebih malas dan konsumtif (Hidayatullah et al., 2018).

Mengacu pada karakteristik generasi milenial yang dijelaskan di atas bahwa generasi milenial cenderung malas dan konsumtif. 1) Segi konsumtif, tentunya berpengaruh pada perilaku konsumtif. Generasi milenial lebih senang menghabiskan uang untuk membeli suatu produk atau menggunakan jasa yang telah disediakan. Milenial merupakan konsumen potensial untuk pelaku bisnis online. Hidayatullah menyatakan konsep perilaku konsumtif adalah membeli barang atau jasa tanpa pertimbangan rasional atau bukan dasar kebutuhan. 2) cenderung malas untuk karakter generasi milenial adalah pada kebutuhan yang telah dipenuhi dengan sekali sentuhan dalam genggaman (teknologi) (Hidayatullah et al., 2018).

Perilaku konsumtif tentunya ada pemicu atau faktor konsumen dalam bertindak. Konsep diri dan motif yang terbentuk dapat dijadikan alasan konsumen bertindak menjadi konsumtif. Dennis Mc Quail membagi pengertian motif dibagi menjadi objektif dan subjektif (Yuniati \& Puspitasari, 2019). Definisi objektif motif merupakan dorongan dari dalam diri individu untuk menentukan pilihannya dari berbagai perilaku tertentu, sesuai dengan tujuan. Definisi subjektif motif merupakan dasar bagi seseorang untuk bergerak, berperilaku, dan bertindak sesuai tujuan atau kegiatan membangkitkan gerak pada diri sendiri untuk mencapai tujuan ataupun kepuasan.

Motif merupakan suatu alasan atau dorongan dalam diri setiap manusia untuk bertindak atau berperilaku yang selanjutnya berhubungan dengan teori kebutuhan Abraham Maslow diantaranya ada kebutuhan fisiologis, kebutuhan kepastian, kebutuhan kasih sayang, dan penghargaan (Sani, 2012).

Venus \& Helmi (2010) menegaskan konsep diri sebagai keseluruhan gambaran seseorang tentang dirinya sendiri. Gambaran ini mencakup keseluruhan persepsi individu tentang karakter dirinya, citra tubuh, kemampuan yang dimilki, emosi serta hubungan dirinya dengan orang lain.

Sarikusuma \& Hasanah (2012) membagi konsep diri berdasarkan perkembangannya yaitu konsep diri primer dan konsep diri sekunder. Konsep diri primer terbentuk berdasarkan pengalamans di rumah, berhubungan dengan anggota keluarga. Konsep diri sekunder berdasarkan lingkungan luar rumah seperti teman, rekan, ataupun relasi sosial lainnya. 
Konsep diri dapat dikategorikan menjadi konsep diri positif dan negatif. Konsep diri positif adalah pemahaman dan penerimaan diri terhadap sejumlah fakta yang ada sehubungan dengan dirinya. Memiliki konsep diri positif merancang tujuan sesuai dengan realitas yang dapat dicapai, mampu menghadapi kehidupan kedepannya. Konsep diri negatif dikarakteristik dengan pandangan yang tidak stabil mengenai dirinya, artinya bahwa individu tidak mengetahui pasti kekuatan, kelemahan dan hal-hal yang harus dihargai dalam hidupnya. Orang-orang dengan konsep diri negatif cenderung perasa dan sulit mernerima kritikan, responsif dan senang dengan pujian, merasa tidak disenangi orang lain, dan bersikap pesimis dalam kompetisi (Sarikusuma \& Hasanah, 2012).

Konsep diri merupakan factor yang sangat menentukan pribadi seseorang (Rohim, 2010). Konsep diri positif tidak sama dengan individu yang sifatnya sombong atau egois, tetapi hal ini lebih mengarah pada penerimaan diri apa adanya, dan mengembangkan harapan sesuai dengan kemampuan yang dimiliki setiap individu. Individu yang memiliki konsep diri negatif adalah menikmati kekurangan dan kelebihan yang ada pada dirinya, mampu menerima saran dan kritik ataupun pujian dari orang lain tanpa tersinggung, serta puas diri sendiri (Andriawati, 2012).

Berbeda dengan individu yang memiliki konsep diri negatif. Informasi yang diterima individu mengenai dirinya cenderung diterima menjadi kecemasan, merasa dirinya terancam. Perasaan cemas dan rendah diri dalam berinteraksi dengan orang lain inilah yang dialami oleh individu yang konsep diri negatif.

\section{Fenomenologi}

Fenomenologi adalah mempelajari bagaimana sebuah fenomena dialami dalam bentuk kesadaran, pikiran dan dalam bentuk sebuah tindakan, serta sesuai dengan kesadaran (Novianti \& Tripambudi, 2014). Fenomenologi juga mencoba mencari pemahaman bagaimana manusia mengkonstruksi makna dan konsep-konsep penting dalam kerangka intersubjektivitas (Kuswarno, 2009).

Generasi milenial dihadapkan pada kemajuan teknologi informasi yang mengharuskan mengikuti perkembangan tersebut. Transaksi digital atau layanan transaksi elektronik salah satunya yang digunakan dalam bertransaksi. Pemahamanmilenialdalammenggunakanlayanan transaksi elekronik terbentuk oleh hubungan individu dengan individu lainnya. Inti dari teori ini adalah bagaimana memahami tindakan sosial yang berorientasi pada perilaku orang atau orang lain pada masa lalu, sekarang dan akan datang.

Terdapat dua tindakan, yaitu pertama; because-motives (Weil-Motiv) yaitu tindakan yang merujuk pada masa lalu, dimana tindakan yang dilakukan oleh seseorang pasti memiliki alasan dari masa lalu ketika melakukannya. Kedua; In-order-to-motive (Um-zu-motiv) yaitu motif yang merujuk pada tindakan dimasa yang akan datang. Dimana, tindakan yang dilakukan oleh seseorang pasti memiliki tujuan yang telah di tetapkan (Kuswarno, 2009).

Motif inilah yang digunakan untuk penelitian ini dimana ada motif masa lalu responden (motif sebab) sebelum menggunakan layanan transaksi digital hingga masuk ke motif akan datang (motif tujuan) yang bersedia menggunakan layanan ini hingga sekarang. Motif merupakan tindakan dalam berbuat sesuatu disertai dengan alasan-alasan atau dorongan-dorongan. Abu mengartikan motif suatu disposisi laten yang berusaha dengan kuat untuk menuju tujuan tertentu, tujuan ini dapat berupa prestasi, afiliasi ataupun kekuasaan (Abu, 2009).

Pengalaman generasi milenial dalam memaknai penggunaan transaksi elektronik pada OVO menjadi dasar pembentukan motif. Motif generasi milenial melakukan tindakan untuk membeli menggunakan layanan OVO. Melalui pengalaman, individu memperoleh pengetahuan dan pengetahuan melandasi kesadaran yang membentuk pemaknaan. Kesadaran dan pemaknaan inilah yang mendorong individu untuk melakukan tindakan atau prilaku tertentu. 
Pandangan Fenomenologi tentang Konsep Diri

Pendekatan fenomenologi adalah tingkah laku tidak hanya dipengaruhi oleh pengalamanpengalaman masa lalu dan saat ini tetapi oleh makna-makna pribadi yang masing-masing individu melekatkannya pada persepsinya mengenaipengalamannyatersebut.Duniaindividu yang sangat pribadi sekali ini yang dengan kuatnya mempengaruhi tingkah laku (Pertiwi, 2018).

Konsep diri adalah individu yang memandang siapa dirinya yang diperoleh melalui informasi orang lain (Mulyana, 2008). Baron dan Donn berpendapat bahwa konsep diri adalah identitas diri seseorang yang terdiri dari kumpulan keyakinan dan sikap terhadap diri sendiri (Baro \& Byner, 2005).

Konsep diri adalah pandangan dan perasaan individu tentang dirinya sebagai hasil dari hubungan dengan orang lain (Rakhmat, 2005). Konsep diri ini juga dijelaskan dalam teori interaksi simbolik dimana adanya hubungan antara simbol dan interaksi yang terjadi dengan perilaku manusia (Sani \& Yohana, 2015).

Berdasarkan pemaparan di atas peneliti ingin mengetahusi motif (masa lalu dan akan datang) dan konsep diri generasi milenial dalam memanfaatkan uang elektronik atau dompet elektronik pada OVO.

\section{Metode Penelitian}

Penelitian ini menggunakan pendekatan kualitatif, dengan pendekatan fenomenologi. Fenomenologi dapat diartikan pengalaman subjektif atau pengalaman fenomenologikal. Pandangan berfikir yang menekankan pada fokus pengalaman-pengalaman subjektif manusia dan interpretasi dunia (Moleong, 2006).

Fenomenologi adalah suatu tradisi untuk mengeksplorasi sebuah pengalaman manusia. Asumsinyaadalahbahwamanusiaaktifmemahami dunia di sekelilingnya sebagai sebuah pengalaman hidupnya dan aktif menginterpretasikan pengalamannya (Littlejohn, W, \& Foss, 2009).
Peneliti mengambil layanan OVO sebagai objek penelitian sedangkan subjek penelitiannya yakni mahasiswa Universitas Muhammadiyah Bandung yang termasuk ke rentang usia generasi milenial. Adapun rentang usia generasi milenial diantara tahun 1980 hingga tahun 2000. Generasi milenial ialah generasi yang hidup di pergantian milenium (Yuswohady, 2016).

Pemilihan informan dengan teknik purposive sampling, yaitu teknik sampling yang menggunakan kriteria terpilih oleh peneliti dalam memilih sampel. Kriteria informan yang dipilih dengan menggunakan pertimbangan tertentu yang sesuai dengan ciri-ciri spesifik yang dimilikinya (Nasution, 2006: 98).

Jumlah mahasiswa generasi Universitas Muhammadiyah Bandung yakni 780 orang. Peneliti menggunakan rumus Slovin sehingga didapatkan 15 informan dari 780. Pengumpulan data dilakukan dengan metode (1) wawancara mendalam yaitu peneliti mewawancarai narasumberyangtelahditentukandanmengajukan pertanyaan berhubungan dengan penelitian, (2) observasi atau pengamatan dimana peneliti mengamati konsep diri dan motif yang dilakukan oleh narasumber dalam menggunakan OVO.

Teknik analisis data yang digunakan adalah reduksi data, penyajian data dan penarikan kesimpulan. Reduksi data adalah melakukan pengumpulan pada informasi penting yang berhubungan dengan penelitian selanjutnya. Peneliti mengelompokkan sesuai dengan kategori yang termasuk dalam konsep, teori maupun topik masalah kemudian mendeskripsikan data sesuai dengan kategori.

Metode analisa data yang digunakan untuk meneliti motif dan konsep diri mahasiswa milenial UMBandung adalah metode reduksi data, penyajian data, dan interpretasi data. Data-data yang sudah sudah dikumpulkan kemudian diklasifikasikan berdasarkan faktor motif dan konsep diri. Pada pelaksanaan proses pengumpulan data dan klasifikasi 
data, berpotensi terdapat dua atau lebih data yang mempunyai pernyataan yang sama. Kondisi tersebut hal yang perlu dilakukan adalah memilih data yang mempunyai sumber data yang paling kuat (sumber data primer).

Setelah data-data yang ada di atas sudah terkumpul dan terklasifikasi, peneliti melakukan penyajian data secara detail dan sistematis agar mudah dipahami. Menyajikan data dalam bentuk narasi dengan menjelaskan setiap data terkait dengan masing-masing konsep tentang motif dan konsep diri dengan pendekatan fenomenologi.

\section{Hasil Penelitian dan Pembahasan Konsep Diri}

Hasil yang ditemukan di lapangan berdasarkan wawancara dengan narasumber yakni konsep diri dan motif dari generasi milenial dalam menggunakan dompet digital OVO berbeda-beda berdasarkan faktor because motives dan in order to motive. Konsep diri berperan dalam tindakan generasi milenial dalam melakukan tindakan.
Mengikuti anjuran Creswell, untuk memaparkan studi fenomenologi, penjelasan harus diawali dengan gambaran umum termasuk di dalamnya gambaran tentang informan yang terlibat (Kuswarno, 2009). Berikut tabel konsep diri yang disusun berdasarkan hasil pernyataan dari narasumber.

Konsep diri yang tergambarkan pada tabel 1 hasilnya sudah terbentuk berdasarkan persepsi mahasiswa akan dirinya dari orang lain. Konsep diri yang terbentuk dijadikan acuan peneliti untuk menganalisis penggunaan layanan dompet elektronik pada OVO. Aplikasi OVO sudah terpasang di handphone masing-masing namun ada yang menggunakan untuk memesan makanan, ada juga yang tidak menggunakan.

"Saya sudah install Grab yang bisa Pakai OVO di HP. Install dikarenakan temanteman saya cerita kalau Pakai Grab banyak promonya dan suka diskon juga di transportasi online. Akhirnya saya coba untuk pakai Grab tapi tidak terlalu sering sih." (Furi dan Anita, 17 Januari 2020)

Tabel 1. Konsep Diri Responden

\begin{tabular}{ll}
\hline \multicolumn{1}{c}{ Mahasiswa } & \multicolumn{1}{c}{ Konsep Diri } \\
\hline $\begin{array}{l}\text { Ayu permata } \\
\text { Citra Lova }\end{array}$ & Kurang pede, moody-an, malas gerak (mager), judes, jutek, dewasa \\
$\begin{array}{l}\text { Nanin Nurhanisah } \\
\text { Mia Rahmawati }\end{array}$ & $\begin{array}{l}\text { Susah bergaul, pilah-pilih teman, ceria } \\
\text { Malas gerak (mager), kepekaan tinggi, receh }\end{array}$ \\
$\begin{array}{l}\text { IIP Syarip } \\
\text { Hidayatullah } \\
\text { Ima Mukaromah }\end{array}$ & $\begin{array}{l}\text { Kurang mudah bergaul ke orang lain, nervous, suka suasana hening, kurang } \\
\text { terbuka dengan orang lain kecuali dengan orang yang sudah di percaya, Sombong }\end{array}$ \\
$\begin{array}{l}\text { Tsabita Rasyida } \\
\text { Rika Dwi }\end{array}$ & $\begin{array}{l}\text { Happy, bercanda, julit } \\
\text { Nurdiyah }\end{array}$ \\
$\begin{array}{l}\text { Muthiah Hadiyati } \\
\text { Sabila }\end{array}$ & Ambisius,terburu buru, baik, murah senyum \\
Nisa Nur Aeni & Peduli, males, Humoris, plin-plan, mager, pintar, childish. \\
Latifah & \\
$\begin{array}{l}\text { M.Dinar Abdul } \\
\text { Malik }\end{array}$ & Ramah, baik, kadang kurang percaya diri, jutek \\
Ali Musa Daud & Lebay, percaya diri, mudah bergaul \\
Furi Junia Defiq & Ramah, pemalas, boros, \\
Anita Putri & Cuek, baik, suka bergaul \\
Meliyanti & \\
Novianti Liana P & Penurut, percaya diri, \\
\hline
\end{tabular}

Sumber: wawancara dan olahan peneliti (2020) 
Beberapa mahasiswa hanya menggunakan layanan transportasi online di Grab dengan OVO dan cash. "Saya mempunyai aplikasi OVO namun hanya untuk keperluan transportasi saja. Ya sekali, dua kali pernah mencoba membeli melalui grab food karena itu juga ada kebutuhan mendesak dan juga malas beranjak ataupun kondisinya memang tidak memungkinkan." (Ayu dan Mia, 17 Januari 2020). Mahasiswa UMBandung memiliki harapan yang tinggi untuk menjadi berguna di masyarakat, mampu menilai dirinya sendiri, serta mampu menyesuaikan dirinya, bisa menilai kelebihan dan kekurangannya dan menghargai dirinya sendiri. Walaupun pada tabel 1 karakter sifat mahasiswa UMBandung ada yang kurang percaya diri, plin plan sensitive namun hal tersebut tidak menjadikan kendala untuk menyesuaikan dengan keadaan.

"Saya senang berkumpul dengan temanteman, berdiskusi apapun itu. Mau tentang kuliah, orang lain, film, korea, isu terbaru, dan lain-lain. Yang penting dapat saling berbagi. Makanya suka dibilang ramah, senang bergaul, walaupun ya cuek juga sih tapi baik." (Ali, Tsabita, Novi. 17 Januari 2020)

Konsep diri itu bukan diihat dari karakter sifat atau fisik yang egois, sombong, sensitif atau tingkat kepekaannya tinggi, tapi lebih menerima keadaan dirinya dan dapat menerima saran kritik orang lain terhadap dirinya tanpa tersinggung.

"Walaupun saya kurang bergaul tapi saya senang dengan adanya saran dan kritikan ke saya. Contohnya saja ketika saya mengerjakan sesuai, tugas ataupun yang lainnya. Ini tuh untuk kebaikan saya menjadi lebih baik lagi. Pengalaman kerja dulu membentuk saya menjadi seperti ini." (Citra, 18 Januari 2020).

Konsep diri pada mahasiswa UMBandung dipengaruhi dari sumber informasi yang dimiliki individu tersebut diantaranya pengalaman masa lalu, pengalaman saat ini, pengalaman orang lain, keadaan fisiologis atau fisik dan emosi. Mahasiswa UMBandung yang memiliki konsep diri positif mampu mengendalikan tindakan situasi yang terjadi dan mampu berinteraksi.
Mengacu pada penelitian (Pertiwi, 2018) bahwa konsep diri ada 3 aspek fisik, psikis (internal) dan sosial. Peneliti mengkategorisasikan konsep diri UMBandung ke dalam dua faktor yaitu internal dan eksternal. Faktor internal yang dijelaskan dari psikis atau sifat individu. Lingkungan keluarga dan pergaulan sosial di luar kampus maupun saat bekerja menjadi faktor eksternal yang dimiliki mahasiswa UMBandung. Luwes, mudah bergaul, percaya diri, humoris, ceria membuktikan bahwa hampir seluruh mahasiswa UMBandung memiliki konsep diri yang baik di eksternal.

Konsep diri yang negatif adalah yang memandang bahwa pribadinya tidak menyenangkan, namun mahasiswa UMBandung menikmati dirinya secara utuh. Sejauh yang peneliti amati, mahasiswa UMBandung sudah merasa nyaman dengan dirinya, menerima diri apa adanya.

Hubungan konsep diri mahasiswa UMBandung dengan perilaku konsumtif dalam penggunaan layanan transaksi OVO, dapat terjadi ketika setiap individu tidak dapat mengendalikan tindakan dalam membeli makanan atau minuman yang ditawarkan. Konsep diri yang dimiliki mahasiswa UMBandung menurut peneliti cenderung ke arah perilaku konsumtif artinya masih dapat disesuaikan.

\section{Motif}

Adapun motif generasi millenial khususnya mahasiswa di Unversitas Muhammadiyah Bandung menggunakan aplikasi OVO dalam penelitian ini dipaparkan berdasarkan hasil wawancara pada tabel 2 .

Berdasarkan tabel 2 bahwa peneliti menganalisis dari sisi motif mahasiswa yang termasuk generasi milenial ada 3 motif: pertama, faktor promo atau diskon atau cashback yang diberikan OVO. Motif dalam memburu promo yang dialami oleh generasi milenial dalam menggunakan aplikasi OVO pernah dialami. Beberapa diantara mahasiswa UMBandung 
Tabel 2: Motif Mahasiswa UMBandung

\begin{tabular}{|c|c|}
\hline Mahasiswa & Motif Tindakan \\
\hline Ayu permata Dewi & Kadang pakai OVO kadang Pakai gopay juga. Tergantung kebutuhan \\
\hline Citra Lova & Praktis saja \\
\hline Nanin Nurhanisah & Pakai OVO karenn ajakan orang, kesini pun jadi suka Pakai karena ada promo-promo jadi lebih murah \\
\hline Mia Rahmawati & Praktis pembayarannya, banyak promonya. Pakai OVO karena keperluan sehari-hari \\
\hline IIP Syarip Hidayatullah & Praktis untuk kemana-mana. Apalagi kalau ada promo \\
\hline Ima Mukaromah & $\begin{array}{l}\text { Pakai OVO karena mudah beli apa saja apalagi kalau lagi malas kemana-mana untuk pesan makaniminum } \\
\text { ataupun mengirim barang }\end{array}$ \\
\hline Tsabita Rasyida & Pakai OVO karena keperluan sehari-hari. Suka saja karena mudah \\
\hline Rika Dwi Nurdiyah & Pakai OVO karena keperluan schari-hari \\
\hline $\begin{array}{l}\text { Muthiah Hadiyati } \\
\text { Sabila }\end{array}$ & Pakai OVO karena keperluan schari-hari \\
\hline Nisa Nur Aeni Latifah & Praktis, Pakai OVO karena keperluan sehari-hari \\
\hline M Dinar Abdul Malik & $\begin{array}{l}\text { Dorongan atau ajakan dari orang terdekat. Praktis juga untuk pembayaran tapi disesuaikan dengan kebutuhan } \\
\text { juga. Ada promo tertarik menggunakannya tapi tidak terlalu signifikan karena tergantung kebutuhan saya. }\end{array}$ \\
\hline Ali Musa Daud & Praktis pembayarannya untuk keperluan schari-hari. Promo senang karena murah. Tapi tidak terlalu signifikan. \\
\hline Furi Junia Defiq & Banyak promosinya, praktis dalam pembayaran, disesuaikan dengan kebutuhan. Kalau lagi ada promo ya beli \\
\hline Anita Putri Meliyanti & Praktis dalam pembayaran dan murah kalau ada promo. Banyak promo di OVO dibandingkan lain \\
\hline Novianti Liana P & $\begin{array}{l}\text { Dorongan atau ajakan kerabat atau teman. Suka lihat promo dan Pakai promo yang cafenya mengikuti promo } \\
\text { dari OVO. Kalau gak ya gak bisa diPakai kode promonya. }\end{array}$ \\
\hline
\end{tabular}

Sumber: Olahan Peneliti (2020)

menyatakan bahwa dalam menggunakan promo diskon ataupun cashback yang ada di aplikasi membuat pembayaran entah itu makan, minuman, berbelanja dan sebagainya menjadi lebih murah.

Di sisi lain ada mahasiswa yang berdasarkan pengalaman bahwa dalam menggunakan promo itu tidak terlalu signifikan dalam menggunakannya karena beberapa promo diambil jika sesuai kebutuhan. Pengalaman lainnya adalah kode promo yang diberikan OVO hanya tempat makan yang telah mengikuti event promo dari pihak OVO dan tersambung pada layanan transportasi online yakni grab. Sama halnya dengan penelitian yang dilakukan oleh (Kusnawan, Diana, Andy, \& Tjong, 2019) bahwa faktor diskon tidak berpengaruh signifikan terhadap minat pembelian impulsif.

Faktor kedua, praktis dalam pembayaran. Era serba digital teknologi memudahkan kita dalam melakukan berbagai hal salah satunya ialah dalam melakukan transaksi pembayaran. Dompet digital tertuama OVO memberikan pelayanan dengan kemudahan penggunanya dalam melakukan pembayaran melalui smartphone mahasiswa UMBandung. Pengguna hanya perlu terhubung dengan koneksi internet untuk menggunakan aplikasi OVO dan memiliki saldo di akun masing-masing.

Mahasiswa UMBandung yang mengguna OVO sebagai dompet digital menyatakan bahwa sangat terbantu sekali dalam melakukan pembayaran. Pengguna tidak perlu repot lagi dalam pembayaran yang dimana jumlah uang yang dikeluarkan dapat sesuai dengan tarif produk yang di inginkan juga pengguna cukup melakukan scan barcode yang sudah disediakan oleh outlet untuk melakukan pembayaran, sehingga tidak perlu ribet untuk mengeluarkan uang dalam dompet. Penelitian yang dilakukan oleh (Paath \& Manurung, 2019) hasilnya sama bahwa dengan adanya layanan transaksi digital dengan model FinTech E-Money Go-Pay di kota Purwokerto dapat diterima masyarakat untuk membantu dan mempermudah kegiatan keseharian terutama dalam transaksi keuangan. 
Faktor ketiga adalah dorongan atau ajakan. Salah satu faktor yang memengaruhi mahasiswa UMBandung dalam menggunakan aplikasi OVO ialah orang terdekat mahasiswa UMBandung bisa orang tua, kakak, ataupun teman. Motifmahasiswa UMBandung menggunakan OVO karena ajakan tentunya telah diberikan penjelasan dari teman, orang tua, kakak, saudara mengenai aplikasi OVO yang dapat digunakan untuk melakukan pembayaran, melakukan transfer uang, serta promo menarik untuk menghemat biaya dalam melakukan transaksi layanan transportasi online ataupun memesan makanan atau minuman.

Motif mahasiswa UMBandung menggunakan layanan transaksi elektronik ada dua kategori yaitu motif karena (because motive) yang merujuk kepada pengalaman masa lalu mahasiswa. Sebelum menggunakan layanan transaksi elektronik, mahasiswa melakukan transaksi jual beli secara tunai serta harus keluar dulu untuk membeli barang atau produk yang diinginkan. Mengacu padapengalaman terdahulu, saat ini mahasiswa UMBandung mengikuti determinasi teknologi atau inovasi keuangan dalam bertransaksi secara non-tunai (cashless). Adapun menginstall atau mengunduh OVO dikarenakan ajakan teman, saudara, atau keluarga.

Motif tujuan (in order to motive) merupakan tujuan yang digambarkan sebagai maksud, rencana, harapan, dan minat yang diinginkan mahasiswa mau menggunakan layanan dompet digital. Minat yang diinginkan, yaitu: dengan menggunakan OVO menambah pengalaman dalam menggunakan inovasi teknologi serta menikmati adanya promo dan adanya keinginan untuk nantinya berganti ke dompet digital yang memberikan pelayanan baik dan memuaskan kebutuhan.

Alfred Scutz juga menjelaskan motif dalam teori fenomenologi adalah seseorang melakukan sebuah tindakan tentunya berdasarkan pada motif sebab (because motive) dan motif tujuan (in order to motive). Sama halnya dengan yang diteliti oleh (Fatikatin \& Handoyo, 2014; Hermaniawati \& Listyani, 2015; Nugraha \& Handoyo, 2015) yang menjelaskan bahwa motif informan dalam berbuat atau melakukan tindakan berdasarkan ajakan, coba-coba. Munculnya motif berawal dari intersubjektifitas yang sehingga dapat menentukan pada motif because of dan motif in order-nya.

Peneliti kategorikan yang menjadi motif sebab dan motif tujuan dari mahasiswa UMBandung dalam bertransaksi elektronik menggunakan OVO.

Tabel 3 menjelaskan hasil atau gambaran kedua motif mahasiswa UMBandung dalam menggunakan layanan OVO. Singkatnya bahwa kedua motif memiliki pemicu baik itu berupa ajakan ataupun berawal dari mencoba kemudian menjadi tertarik karena faktor kebutuhan. Kebutuhan untuk relaksasi terdiri dari memesan sesuatu lebih cepat, merasa lebih nyaman dan aman ketika bertransaksi, tidak merasa khawatir terhadap keuangan dan mempermudah pembayaran. Kebutuhan untuk shopping merupakan kebutuhan ingin mendapatkan informasi tentang barang dan membeli produk yang diinginkan. Hal ini terhindar dari sifat manusia yang suka bosan dari menu makanan yang setiap hari sama.

Setiap manusia jika sudah mencapai tahap termotivasi, maka keadaan internal yakni konsep diri tersebut yang merangsang seseorang untuk bertindak ke arah tertentu dan menahannya untuk menjalankan aktifitas tersebut dan kemudian sampailah mahasiswa UMBandung kepada perilaku yang konsumtif.

Tabel 3. Tipologi motif because dan in order to

\begin{tabular}{ll}
\multicolumn{1}{c}{ Because Of } & \multicolumn{1}{c}{ In Order To } \\
\hline Pemanfaatan waktu & $\begin{array}{l}\text { Keinginan untuk berpindah layanan } \\
\text { jika tidak sesuai harapan }\end{array}$ \\
Tidak tertarik & Ajakan orang lain \\
Pembayaran masih cash & Harapan Mendapatkan promo \\
Malas gerak atau mager & Praktis membayar \\
\hline
\end{tabular}

Sumber: Hasil olahan peneliti (2020) 
Era disrupsi memudahkan setiap individu mendapatkan informasi melalui teknologi sehingga mempengaruhi manusia untuk berperilaku konsumtif. Perilaku konsumtif adalah dimana manusia membeli barang atau menggunakan jasa tanpa pertimbangan rasional bukan dasar kebutuhan. Jika dihubungkan dari konsep diri, motif yang dapat dilihat pada tabel 3 tentu berhubungan untuk menimbulkan perilaku konsumtif.

Mahasiswa UMBandung terlihat mampu mengendalikan perilaku penggunaan OVO, namun mahasiswa milenial belum dapat mengendalikan keputusan dalam membeli jika adanya promo besar-besaran, cashback yang ditawarkan. Pengendalian pengetahuan mengenai promo maupun cashback belum sepenuhnya diketahui oleh mahasiswa. Mahasiswa UMBandung dari hasil di atas ada yang terkadang hanya mengikuti keinginan dan kekinian untuk membeli produk yang ditawarkan.

Penelitian yang dilakukan oleh Hidayatullah et al., (2018), Rif'ah, (2019), Wijayanti \& Astiti, (2017) yang melihat dari segi pola dan perilaku konsumtif bahwa adanya kemudahan sistem cashless dan kecenderungan untuk malasndalam bertransaksi berpengaruh kepada pembelian yang sering. Perilaku konsumtif juga berhubungan dengan konsep diri yang terbentuk dari seseorang baik itu negatif dan positif. Hasil dari penelitian ini adalah konsep diri negatif.

\section{Pemaknaan Transaksi Digital}

Di era perkembangan teknologi informasi sudah menjadi sesuatu yang lumrah di generasi milenial. Mahasiswa UMBandung memaknai transaksi digital tidak hanya sebagai alat transaksi saja tetapi dapat dikatakan sebagai teman di saat darurat. Darurat seperti malas beranjak untuk keluar rumah atau kosan, bosan dengan menu yang sama. Segi kepraktisan, penawaran promo, keamanan di uang elektronik, dan inovasi keuangan. Teknologi membuat kemudahan dalam bertransaksi dimanapun dan kapanpun tanpa khawatir keamanannya. Pengalaman menurut Alfred Scutz menghubungkan antara pengetahuan ilmiah dengan pengalaman seharihari dan dari kegiatan pengalaman itu berasal. Artinya adalah berdasarkan pada tindakan sosial pada pengalaman, makna, dan kesadaran (Kuswarno, 2009: 17)

Kemudahan dalam mencari informasi untuk kebutuhan milenial yakni dalam bertransaksi digital untuk menggunakan jasa ataupun memerlukan barang berefek pada perilaku ke konsumtif ataupun sesuaikan kebutuhan. Pengalaman sehari-hari milenial saat ini tentunya sudah bersentuhan dengan teknologi sehingga tidak bisa menampik adanya teknologi.

\section{Simpulan}

Hasil penelitian mengenai fenomena dompet digital pada generasi Millenial yaitu: 1) Mahasiswa memiliki motivasi dalam penggunaan aplikasi OVO yaitu pada shopping dan relaxation dimana Faktor shopping terdiri dari mendapatkan informasi tentang barang dan membeli produk yang diinginkan, sedangkan faktor relaxation terdiri dari memesan sesuatu lebih cepat, merasa lebih nyaman dan aman ketika bertransaksi, tidak merasa khawatir terhadap keuangan dan mempermudah pembayaran. Melaluipengalaman yang terbentuk dari penggunaan dompet digital OVO secara konsumtif tersebut, sadar atau tidak sadar, para mahasiswa telah membentuk konsep dirinya sendiri yang cendrung ke arah negatif yang menimbulkan dampak seperti boros keuangan dan timbulnya rasa malas; 2) Motif mahasiswa Universitas Muhammadiyah Bandung menggunakan aplikasi OVO dalam melakukan transaksi dipengaruhi oleh motif sebab (because motive) dan motif harapan atau tujuan (in order to motive). Motif sebab (because motive) yang menjadi latar belakang mahasiswa menggunakan Aplikasi OVO adalah karena dorongan dari kerabat terdekatnya yaitu orang tua, saudara, bahkan teman yang sudah 
menggunakan aplikasi OVO. Motif tujuan atau harapan (in order to motive) yang menjadi tujuan mahasiswa menggunakan OVO ialah agar bisa mendapatkan promo dalam membayar sesuatu seperti makanan ataupun transportasi. Tidak hanya itu para mahasiswa juga bisa lebih praktis dalam membayar dengan uang pas serta tidak perlu ribet untuk mengeluarkan uang dalam dompet. Serta adanya keinginan untuk berganti ke dompet digital yang memberikan pelayanan baik dan memuaskan kebutuhan.

Kontribusi penelitian ini berupa rekomendasi kepada perusahaan OVO, Gopay, DANA, LinkAja agar memudahkan layanan transaksi dengan menambahkan gerai-gerai yang dapat mengikuti promo.

\section{Daftar Pustaka}

Abu, A. (2009). Psikologi Sosial. Jakarta: In Rineka Cipta. Andriawati, S. (2012). Hubungan Konsep Diri dengan Kecemasan Narapidana Menghadapi Masa Depan di Lembaga Pemasyarakatan Wanita Malang (Universitas Islam Negeri Maulana Malik Ibrahim Malang). Retrieved from http://etheses.uin-malang. ac.id/2212/2/07410138_Indonesia.pdf

Baro, R. ., \& Byner, D. (2005). Psikologi Sosial. Jilid 2. Alih Bahasa: Ratna Djuwita. In Psikologi Sosial. Jakarta: Erlangga. Bintarto, E. (2018). Fintech dan Cashless Society: Sebuah Revolusi Mendongkrak Ekonomi Kerakyatan. Call For Essays, 1-77. Fatikatin,Y.,\&Handoyo,P.(2014).MotifTransaksi Ecommerce Bagi Mahasiswa di Surabaya. Jurnal Paradigma, 2(1), 1-5. Diakses dari https://jurnalmahasiswa.unesa.ac.id/ index.php/paradigma/article/view/6872

Fauzie, Y. Y. (2019). Jangan Konsumtif Gara-gara Segudang Diskon Dompet Digital. Retrieved from https://www.cnnindonesia.com/ ekonomi/20190914095419-83-430437/ j a n g a n - k on s u m t i f-gar a - gar a segudang-diskon-dompet-digital
Hermaniawati, N., \& Listyani, R. H. (2015). Motif Pemanfaatan Layanan Elektronik Tiket (E-Ticketing) oleh Pengguna Kereta Api di Surabaya. Jurnal Paradigma, 3(03), 1-7. Diakses dari https://jurnalmahasiswa.unesa.ac.id/ index.php/paradigma/article/view/13046 Hidayatullah, S., Waris, A., \& Devianti, R. C. (2018). Perilaku Generasi Milenial dalam Menggunakan Aplikasi Go-Food. Jurnal Manajemen Dan Kewirausahaan, 6(2), 240-249. https:// doi.org/10.26905/jmdk.v6i2.2560 Houston, D. D. (2020). Adopsi Penerimaan Digital Payment Pada Kalangan Milenial. MEDIUM, 7(2), 55-67. https://doi. org/10.25299/medium.2019.vol7(2).4094

Kusnawan, A., Diana, S., Andy, \& Tjong, S. (2019). Pengaruh Diskon pada Aplikasi e-Wallet terhadap Pertumbuhan Minat Pembelian Impulsif Konsumen Milenial di Wilayah Tangerang. Jurnal Sains Manajemen, 5(2), 137-160. https://doi.org/10.30656/sm.v5i2.1861 Kuswarno,E.(2009). Fenomenologi, Metodologi Penelitian Komunikasi, Konsepsi, Pedoman, dan Contoh Penelitian. Fenomena Pengemis Kota Bandung. 264 pages. Littlejohn, W, S., \& Foss, K. A. (2009). Teori Komunikasi (9th ed.). Jakarta: Salemba Humanika . Moleong, L. J. (2006). Metodelogi Penelitian Kualitatif (revisi ed.). Bandung: PT Remaja Rosdakarya. Mulyana, D. (2008). Metode Penelitian Kualitatif Paradigma Baru Ilmu Komunikasi dan Ilmu Sosial Lainnya. Bandung: PT Remaja Rosdakarya. Nasution, S. (2006). Metode Research. In Metode Research. Jakarta: Bumi Aksara. Novianti. D., \& Tripambudi, S. (2014). Studi Fenomenologi: Tumbuhnya Prasangka Etnis di Yogyakarta. Jurnal Ilmu Komunikasi, 12(2), 119-135. Diakses dari http://jurnal.upnyk.ac.id/ index.php/komunikasi/article/view/368 
Nugraha, J. P., \& Handoyo, P. (2015). Punk dan Keluarga: Studi Fenomenologi Motif Menjadi Punkers dalam Lingkup Keluarga Januar Putra Nugraha Pambudi Handoyo. Paradigma, 3(2), 1-7. Diakses dari https://jurnalmahasiswa.unesa.ac.id/ index.php/paradigma/article/view/11346

Paath, D. K., \& Manurung, R. (2019). Analisis Persepsi PenggunaLayanan Transaksi Digital Terhadap Financial Technology (Fintech) Dengan Model E-Money (Studi kasus: layanan Go-Pay "Gojek" di Purwokerto). Jurnal HUMMANSI (Humaniora, Manajemen, Akuntansi), 2(2), 38-45. https://doi.org/10.33488/1.jh.2019.2.226

Pangestu, S. (2020). Riset: dompet digital mendorong Generasi $\mathrm{Z}$ lebih konsumtif. Retrieved from https://theconversation. com/riset-dompet-digital-mendoronggenerasi-z-lebih-konsumtif-129243

Pertiwi, A. (2018). Studi Fenomenologi Tentang Konsep Diri Wanita Shopaholic di Kota Bandar Lampung. Lampung.

Prama, N. (2020). GoPay Ternyata Jadi Dompet Digital Paling Diminati Generasi $Z$ dan Milenial. Retrieved from https:// nextren.grid.id/read/012024532/gopayternyata-jadi-dompet-digital-palingdiminati-generasi-z-dan-milenial?page $=$ all

Rakhmat, J. (2005). Psikologi Komunikasi. In Psikologi Komunikasi. Rif'ah, S. (2019). Fenomena Cashless Society Di Era Milenial Dalam Perspektif Islam. AlMusthofa: JournalofShariaEconomics, 2(1), 1-14. Diakses dari http://ejournal.iai-tabah. ac.id/index.php/musthofa/article/view/360

Rohim, S. (2010). Konsep Diri Eks Wanita Tuna SusiladiPantiSosial.JurnalIlmuKomunikasi, 8(1), 45-57. Diakses dari http://jurnal.upnyk. ac.id/index.php/komunikasi/article/view/68

Rosmayanti. (2019). Apa Itu Dompet Digital? Retrieved from https://www. wartaekonomi.co.id/read212834/ a p a - i t u - d o mpet-digita l.ht m 1
Sani, F. L., \& Yohana, N. (2015). Fenomena Komunikasi Anggota Komunitas Graffiti di Kota Medan (Studi Fenomenologi Pada Anggota Komunitas ME\&ART). JOM FISIP, 2(2), 54-67. Diakses dari https://jom.unri.ac.id/index. $\mathrm{ph} \mathrm{p/J} \mathrm{O} \mathrm{MF} \mathrm{S} \mathrm{IP} \mathrm{/} \mathrm{a} \mathrm{rt} \mathrm{i} \mathrm{c} \mathrm{le/vi} \mathrm{ew} \mathrm{/} 4856$ Sani, M. B. (2012). Gaya Hidup Baru Kaum Urban: Motif dan Perilaku Pelaku Futsal. Universitas Gadjah Mada. Sarikusuma, H., \& Hasanah, N. (2012). Konsep Diri Orang Dengan HIV Dan AIDS (ODHA) yang Menerima Label Negatif dan Diskriminasi dari Lingkungan Sosial. Psikologia: Jurnal Pemikiran dan Penelitian Psikologi, 7(1), 29-40. Diakses dari https:// talenta.usu.ac.id/jppp/article/view/2533 Sutriyanto, Eko. (2019). 3 Besar Dompet Digital IndonesiaUntuk Transaksi Ritel, Transportasi dan Pengiriman Makanan Online. Retrieved from tribunnews.com website: h t t ps : / / w w w tribunnews . com/ techno/2019/07/15/3-besar-dompet-digitalindonesia-untuk-transaksi-ritel-transportasidan-pengiriman-makan an-online Venus, A., \& Helmi, L. (2010). Budaya Populer Jepang di Indonesia: Catatan Studi Fenomenologis Tentang Konsep Diri Anggota Cosplay Party Bandung. ASPIKOM, 1(1), 71-90. http:// dx.doi.org/10.24329/aspikom.v1i1.9 Wijayanti, A., \& Astiti, D. P. (2017). Hubungan Antara Konsep Diri Dengan Perilaku Konsumtif Remaja di Kota Denpasar. Jurnal Psikologi Udayana, 4(1), 4149. doi:10.24843/JPU.2017.v04.i01.p05

Wirman, W. (2012). Pengalaman Komunikasi dan Konsep Diri Perempuan Gemuk. IJAD: Indonesian Journal of Dialectics, 2(2). Diakses dari http://jurnal. unpad.ac.id/ijad/article/view/2659 Wulandari, S. (2016). Motif dan Makna Diri Penata Rias di Kota Pekanbaru dalam Perspektif Fenomenologi. JOM FISIP, 3(2), 
1-14. Diakses dari https://jom.unri.ac.id/ index.php/JOMFSIP/article/view/11309

Yuniati, U., \& Puspitasari, E. E. (2019). Motif Pendengar Radio Di Era Perkembangan Teknologi Informasi (Studi Kepuasan Penggunaan Media Pada Generasi Z
Di Bandung). Jurnal Ilmu Komunikasi [JIKA], 6(2). https://doi.org/https://doi. org/10.31294/kom.v6i2.6504.g3631 Yuswohady. (2016). Millennial Trends 2016. Retrieved from https://www.yuswohady. com/2016/01/17/millennial-trends-2016/ 